dos tribunais especializados. Ranft teria melhor compreendido a sua tarefa, tivesse ele refletido sobre como se pode restituir à reserva do juiz a função de uma proteção jurídica preventiva, diante de uma práxis deteriorada nas operações de busca e apreensão ${ }^{78}$.
5. Somente com essa reflexão seria possível garantir uma das áreas mais sensíveis dos direitos fundamentais da pessoa, a saber a liberdade de buscas injustificadas, e impedir a transgressão da fronteira entre o Estado de Direito e o estado policial ${ }^{79}$

\section{Integração Jurídica na Europa}

\section{Haxniet Christiane Litschex}

Professora Visitante DAAD/CAPES na Faculdade de Direito da Universidade Federal do Rio Grande do Sul; Doutora em Direito pela Universidade de Hamburgo, Alemanha.

Agradeço a minha cara colega Professora Doutora Clándia Lima Marques que sugeriu e facilitou a produçāo e publicação deste artigo (que apresentei - de forma muito abreviada - como palestra durante o "VI Encuentro de Especialistas en el Mercosur", Rosário, Argentina, 27 e 28 de agosto de 1998) e providenciou material valioso durante viagem ao exterior, ao meu colega, Professor Doutor Luís Afonso Heck, por uma discussão estimulante, ao assistente universitario Cristian Schindler, Heidelberg; que forneceu fontes aqui dificilmente acessíveis e ao bolsista Anderson de Lima Kovalsky, sern cuja ajuda, tanto no âmbito técnico como no âmbito lingüístico, este artigo nunca teria sido escrito. Partes deste trabalho já foram publicadas sob o titulo "Probleme eines Wandels des innerstaatlichen Rechts zu einem europäischen Rechtssystem nach der Rechtsprechung des Europäischen Gerichtshofs" in: RabelsZ 60 (1996) pp. $648-660$ pela própria autora.

\begin{tabular}{|l|l|}
\hline \multicolumn{2}{|c|}{ SUMÁRIO } \\
I. Introdução. & III. A Diretiva como Instrumento Especial da \\
II. Aspectos gerais. & Integração Jurídica. \\
1. O Tribunal das Comunidades Européias na & 1. Nota Preliminar. \\
Estrutura da Comunidade Européia. & 2. Aplicação da Diretiva Não-transformada \\
a. No texto do Tratado da Comunidade & como Sanção. \\
Européia. & a. Necessidade de uma sanção. \\
b. Na realidade. & b. Sanção do efeito direto. \\
c. Osmétodos interpretativos do Tribunal CE. & c. Quiebra da idéia da sanção-Art. 5 Tra- \\
2. Direito Europeu como Sistema Jurídico e & tado CE. \\
as suas Fontes Principais. & 3. Indenização por Falta de Transformação. \\
a. Particularidades do Direito Europeut. & 4. Diretiva e Interpretação. \\
b. Fontes principais de Direito Europeu. & a. Nota preliminar. \\
c. A diretiva: uma norma com caráter es- & b. Interpretação e aplicação. \\
pecifico. & c. Interpretação e solução de conflito de \\
3. Direito Europeu e Direito Nacional. & normas. \\
a. Princípio da subsidiaridade. & d. Abalo de direito interno. \\
b. Primazia. & e. O problema dos métodos. \\
c. Vigência e aplicação. & IV. Conclusões e uma Sugestão. \\
\hline
\end{tabular}

Revista da Faculdade de Direito da UFRGS, v. 16, 1999
78. Cf. para tal também Papier/Dengler, BB 1996, 2541 (2548)

Revista da Faculdade de Direito da UFRGS, v. 16, 1999 


\section{Introdução}

o Tribunal da Justiça das Comunidades Européias (Tribunal CE) se atribui cada vez mais, nos últimos anos, o papel do promotor da integração européia através do desenvolvimento do direito ${ }^{1}$.

Talvez o instrumento mais impressionante que o Tribunal CE utiliza nesse processo é a interpretação e aplicação das diretivas, especialmente das diretivas que harmonizam o direito privado ${ }^{2}$. Como norma, a diretiva tem caráter especial, como se verá a seguir.

\section{Aspectos gerais}

\section{O Tribunal das Comunidades Européias na estrutura da Comunidade Européia}

\section{a. No texto do Tratado da} Comunidade Européia

Conforme o art. 4 do Tratado da Comunidade Européia (Tratado CE), o Tribunal das Comunidades Européias (Tribunal CE) é um dos cinco órgãos das Comunidades Européias (CE). O art. 164 do Tratado CE estabelece que o Tribunal interpreta e aplica o Tratado cuidando do direito ${ }^{3}$ neste processo.

Há um processo especial, o processo prejudicial, onde os tribunais nacionais podem ou têm que - dependendo da instância - interromper um processo pendente e submeter uma questão prejudicial de Direito Europeu no que depende à decisão do tribunal nacional ao Tribunal CE. Neste processo prejudicial regulado pelo art. 177 Tratado CE, o Tribunal só interpreta o Tratado e, em conformidade com isso, a aplicação ficará a cargo dos tribunais dos Estados-membros ${ }^{4}$.

\section{b. Na realidade}

Em comparação com o Conselho e a Comissão, que são órgãos basicamente políticos, o Tribunal CE é mais capaz de agir ativamente e com continuidade na realização efetiva do Tratado CE. Especialmente em tempos de estagnação política no processo da integração ${ }^{5} \mathrm{o}$ Tribunal CE tornouse a força principal deste processo.

Nesse caminho, o Tribunal necessariamente desenvolveu métodos próprios de interpretação e aplicação das normas ${ }^{6}$, que nem sempre encontraram aprovação indivisa?

1. Ver por todos Bengt Beutler/ Roland Bieber/ Jörn Pipkorn/Jochen Streil, Die Europäische Union Rechtsordnung und Politik (4 ed., Nomos, Baden-Baden 1993) p. 236 ss.

2. Comparar Marek Schmidt, Privatrechtsangleichende EU-Richtinien und nationale Auslegungsmethoden, RabelsZ 59 (1995) pp. 569-597.

3. Para o entendimento do conceito "direito" neste trabalho ver o artigo de Marek Schmidt, Die vorpositive Bedeutung des Begriffs Recht in Art. 164 EGV, 136 EAGV und 31 EGKSV, RabelsZ 60 (1996) pp. 616-647.

4. Para o efeito gerador do direito dos acórdãos do Tribunal CE ver Beutler/Bieber/Pipkorn/Streil, (nota 1), pp. $259 \mathrm{ss}$.

5. Beutler/Bieber/Pipkorn/Streil, (nota 1), p. 236 ss.

6. Ver por todos Beutler/Bieber/Pipkorn/Streil, (nota 1), p. 239; Marek Schmidt, (nota 2).

7. Hans-Werner Rengeling/ Andreas Middeke/ Martin Gellermann, Rechtsschutz in der Europäischen Union (Schriftenreihe NJW 56, C. H. Beck, München 1994), p. 501; Martin Pagenkopf, Zum Einfluß des Gemeinschaftsrechts auf nationales Wirtschaftsverwaltungsrecht - Versuch einer praktischen Einführung, NVwZ 1993, pp. 216-225, p. 220.; Stefan Ulrich Pieper, Die Direktwirkung von Richlinien in der Europäschen Gemeinschaft, DVBI. 1990, pp. 684-688, p. 688; Holger Stadie, Unmittelbare Wirkung von EG-Richtlinien und Bestandskratt von Verwaltungsakten NVwZ, 1994, pp. 435-440, p. 440.

c. Os métodos interpretativos do

Na hermenêutica do Tribunal prevalece o método teleológico da interpretação. O telos desta interpretação é o effet util, isto é, efeito útil do Direito Europeu no território da Comunidade Européia ${ }^{8}$. Em contras te com os cânones da interpretação nos ordenamentos jurídicos nacionais dos Es tados-membros, a interpretação literal tem importância mínima, pois todas as versões do Tratado CE nas diferentes línguas européias são texto autêntico e autoritativo. Este fato em si já torna difícil a utilização deste método, que é dificultado ainda mais pelas contradições entre as diferentes versões? 9 .

\section{Direito Europeu como sistema jurídico e as suas fontes principais}

\section{a. Particularidades do Direito} Europeu

O direito da Comunidade (e União) Européia tem algumas particularidades. É uma ordem jurídica criada por um Tratado Internacional, uma ordem específica que se Tribunal CE

distingue tanto do direito internacional público como do sistema tradicional do direito naciona ${ }^{10}$. É preciso destacar a dinâmica inerente dessa ordem jurídica européia que se originou e se baseia na finalidade da integração política e está, também, mantida por esta finalidade ${ }^{11}$.

Além disso, é particular da ordem jurídica européia uma separação insuficiente de poderes nos processos legislativos ${ }^{12} \mathrm{e}$ uma certa falta de transparência na publicidade das normas ${ }^{13}$.

\section{b. Fontes principais de Direito}

\section{Europeu}

Distingue-se, principalmente, entre fontes primárias e secundárias de Direito Europeu. As fontes primárias são os trata$\operatorname{dos}^{14}$ e os seus protocolos ${ }^{15}$.

Como fontes primárias de Direito Europeu existem, além disso, os princípios jurídicos gerais ${ }^{16}$, comuns aos ordenamentos jurídicos dos Estados-membros. Os princípios comuns têm base no art. 215 II do Tratado CE, a serem aplicados nos casos de responsabilidade extracontratual da Comu-

8. Beutler/Bieber/Pipkorn/Streil, (nota 1), pp. $247 \mathrm{~s}$

9. Beutler/Bieber/Pipkorn/Streil, (nota 1), pp. $245 \mathrm{~s}$.

10. TCE: 15/07/1964, Rs. $6 / 64$ (Costa./.ENEL) Slg. 1964, 1251 (1269); Rengeling/Middeke/Gellermann, (nota 7), pp. 476 ss.

11. Beutter/Bieber/Pipkorn/Streil, (nota 1), pp. 236; ver também Pagenkopf, (nota 7), p.219.

12. Stefan Ulrich Pieper, Der Maastrichter Vertrag, em: Carl Otto Lenz/ Rolf Birk/ Stefan Ulrich Pieper, EG-Handbuch. Recht im Binnenmarkt ( $2^{\mathrm{a}}$ ed., Verlag Neue Wirtschaftsbriefe, Berlin 1994), pp. 907-943, 931 $\lrcorner$ ss., Pieper, (nota 7), p. 688; Stadie, (nota 7), pp. 437 ss.

13. Pagenkopf, (nota 7), pp. 222, 224.

14. Sobre: Comunidade Européia de Carvão e Aço de 18 de abril de 1951, Comunidade Econômica Européia e Comunidade Euro. péia de Energia Nuclear de 25 de março de 1957, Uniäo Européia de 7 de fevereiro de 1992 - Maastricht, que entrou em vigor em $1^{2}$ de novembro de 1993 apud Thomas Läufer (ed.), Europäische Union - Europäische Gemeinschaft. Die Vertragstexte von Maastricht ( $5^{\mathrm{a}}$ ed., Europa Union Verlag, Bonn 1996).

15. Frank Emmert, Europarecht ( C. H. Beck, München, 1996), p. 123.

16. Considerados como fonte primária não escrita, comparar Beutler/Bieber/Pipkorn/Streil (nota 1), pp. $188 \mathrm{~s}$. 
nidade e dos seus órgãos e funcionários. $\mathrm{O}$ Tribunal CE, entretanto, ampliou o âmbito de aplicação destes princípios ${ }^{17}$.

Das fontes secundárias, são as mais importantes o regulamento e a diretiva, que têm base no art. 189 do Tratado CE. Por fim, note-se que a jurisprudência do Tribunal CE exerce, como fonte de direito especial uma importância muito maior do que a jurisprudência dos tribunais nacionais nas ordens jurídicas nacionais ${ }^{18}$.

\section{c. A diretiva: uma norma com caráter específico}

A diretiva do Direito Europeu não só é medida freqüentemente utilizada ${ }^{19}$ para a harmonização dos sistemas dos Estadosmembros, mas também é um instrumento legislativo específico ${ }^{20}$.

Por um lado, conforme a letra do art. 189 III Tratado CE, a diretiva dirige-se somente aos Estados-membros e carece de

uma transformação para a ordem jurídica interna para vigorar no território nacional. Por outro lado, também, de acordo com a letra do art. 189 III do Tratado CE, a diretiva obriga o Estado somente com o fim da diretiva, deixando a escolha de medidas para atingir aquele fim aos Estados-membros $^{21}$. Assim, a diretiva, como norma, tem caráter especial. Primeiro, a diretiva é o primeiro passo de um processo legislativo bipartido, e o segundo passo deste processo é o ato legislativo ${ }^{22}$ do Estado-membro transformando-a dentro do prazo estabelecido nela para o ordenamento jurídico interno $^{23}$. Segundo, a diretiva, por ser (como um passo só de um processo bipartido) incompleta, mostra-se mais flexível frente à interpretação do que uma norma jurídica completa - de um sistema nacional:

Um fim fica no futuro ${ }^{24}$ e aí o estado desejado apresenta um elemento de incerteza. Contanto que se trate de fim social (e não de fim físico), torna-se impossível des-

17. Emmert, (nota 15), p. 133

18. Emmert, (nota 15), p. 134.

19. Volkmar Götz, Europäische Gesetzgebung durch Richtlinien - Zusammenwirken von Gemeinschaft und Staat, NJW 1992, pp. 1849-1857, 1850; Pagenkopf, (nota 7), p. 222.

20. Stefan Grundmann, EG-Richtlinie und nationales Privatrecht, JZ 1996, pp. 274-287, pp. 274s.; M. Schmidt, (nota 2), p. 570; Götz, (nota 19), p.1850.

21. Esta obrigação pelo fim da diretiva tem efeito já antes da transformaçăo da diretiva, porque proíbe ao Estado-membro todas as medidas legislativas que dificultam a transformação posterior, TCE: 18/12/1997, Rs. C-129/96 (Inter-Environnement Wallonie), Sig. 199717411 (7449 s.).

22. A transformação tem que ser uma medida estadual suficientemente clara, completa e transparente (publicada devidamente); não basta uma referência geral ao dever dos serviços públicos aplicar a diretiva no futuro, TCE: 20/03/1997, Rs. C-96/95 (Kommission.)

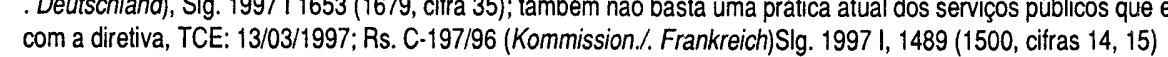

23. Albrecht Bach, Direkte Wirkungen von EG - Richtlinien, JZ 1990, pp. 1108-1116, p. 1109; Stadie, (nota 7), p. 440.

24. Comparar Jacob Grimm/Wilhelm Grimm, Deutsches Wörterbuch, Fünfzehnter Band, Z-Zmasche, redigido por Moriz Heyne/Henry Seedorf/Hermann Teuchert( (Verlag von S. Hirzel, Leipzig 1956), "Fim... parece que o sentido básico reside no conceito de 'medir determinar o ponto final de um movimento' e precisamente, no sentido de uma imagem, noçäo pontual, que pode ser provada como primitivo tanto como sentido temporal, quanto como sentido espacial..." (tradução livre e destaque pela autora).

Revista da Faculdade de Direito da UFRGS, v. 16, 1999

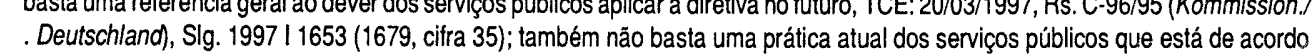

crever, exatamente, numa maneira indubitável, o estado que deve reinar no momento em que se atinge esse fim $^{25}$.

Somente o Tribunal CE determina se foi alcançado o fim da diretiva. O Tribunal, como única instância, é que pode e deve decidir com força obrigatória se a diretiva foi transformada devidamente ou não.

- Em qualquer outro momento, por qualquer outro observador, a realização do fim fica incerta e aí a interpretação do fim fica dinâmica. Aparentemente, o caminho crição do Estado-membro. Na verdade, o Tribunal interpretador determina tanto o caminho como o fim ${ }^{26}$, pois poderia estabelecer, caso a caso, que o caminho escolhido pelo Estado-membro não tem como chegar ao fim. A liberdade do Tribunal, no campo da interpretação mostra-se com nitidez exemplar nos casos em que o fim não está formulado claramente ${ }^{27}$. Esta li berdade de interpretação especial do Tribunal no caso das diretivas, possibilitou a uma atividade inovadora do Tribunal que intervem, fortemente, nos sistemas jurídicos nacionais. para chegar naquele fim inclui-se na dis-

\section{Direito Europeu e direito} nacional

\section{a. Princípio da subsidiaridade}

O Tratado de Maastricht fundou a União como estrutura, abrangendo a Comunidade Européia, a moeda única e uma cooperação, prevalentemente ainda intergovernamental, entre os Estados-membros nas áreas da política externa e interna. Como vários Estados-membros mostraram receio de assinar um Tratado que ampliou tanto as competências dos órgãos de uma entidade européia cada vez mais centralizada, incorporou-se nas negociações, expressamente, o princípio de subsidiaridade (art. 3b) no Tratado CE para contrabalançar os poderes crescentes da Comunidade ${ }^{28}$.

Este princípio, só se aplica nas áreas em que a Comunidade ainda não tem competência exclusiva ${ }^{29}$. Ele só concede competência à Comunidade nas demais matérias, se o fim da medida pretendida não pode ser alcançado, suficientemente, no plano dos Estados-membros e se - cumulativamente - a Comunidade pode alcançar este fim de uma maneira melhor ${ }^{30}$.

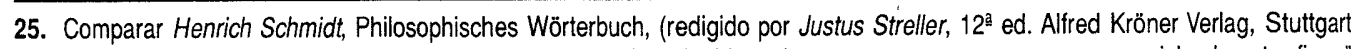
1951), p. 645 , sobre a diferença entre Zwecke Ziel: "... o fim atingido pode mostrar-șe como um passo no caminho de outro fim..." 1951), p. 645, sobre a diferenç

26. Por exemplo, ver a Diretiva contra Discriminação entre os Sexos 76/207 EWG, Abl. EG 1976 L 39/40, e a avaliação da transtormaçăo dela para 0 ordenamento interno da Alemanha pelos órgão da CE: Rolf Birk, Arbeitsrecht - Freizügigkeit der Arbeitnehmer

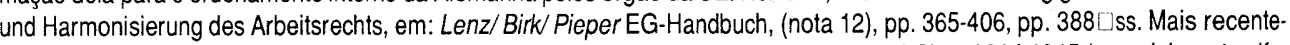
mente ver o acórdăo TCE: 08/10/1996, Rs. C-178, 179, 188, 189 e 190/94 (Dillenkofer u.a.) Slg. 1996 I 4845 (especialmente cifra 43, 4883).

27. Ver para isto Klaus Hansmann, Schwierigkeiten bei der Umsetzung und Durchführung des europäischen Umweltrechts, NVwZ 1995, pp. 320-325, pp. $321 \mathrm{~s}$

28. Emmert, (nota 15), pp. 170 s

29. Emmert, (nota 15), p. 174

30. Beutler/Bieber/Pipkorn/Streil, (nota 1), pp. 84 s.; Emmert, (nota 15), p. 176 
Existem sérias dúvidas se este princípio é idôneo para ser aplicado em juízo ${ }^{31}$. Mas existe, também, uma certa probabilidade de que o Tribunal CE tenha inclinação de não invalidar legislação comunitária por ferir o princípio da subsidiaridade continuando, entretanto, com a regra in dubio pro communitate; isso, especialmente, porque o Tribunal $\mathrm{CE}$ tem interesse inerente a tornar comunitárias novas áreas do direito (quer dizer, acolher sob a sombra da CE), processo que vai ampliar a sua esfera de influência ${ }^{32}$.

\section{b. Primazia}

As normas do Direito Europeu quando são aplicáveis - têm prioridade absoluta perante o direito doméstico dos Estados-membros. Esta é a regra principal, que é resultado de um desenvolvimento jurisprudencial que começou já no anos sessenta ${ }^{33}$.

Esta prioridade vigora sobre todo o direito nacional; "direito nacional", neste sentido, inclui, no entendimento do Tribunal CE, até os direitos básicos e princípios fundamentais das Constituições dos Estados-membros - entendimento nem sempre e só parcialmente compartilhado pelos tribunais constitucionais nacionais ${ }^{34}$.
A prioridade do Direito Europeu, porém, não anula a norma do direito nacional nas matérias que abrange, mas a torna inaplicavél, no âmbito da diretiva, deixando a mesma norma de direito nacional aplicável em outras matérias, por exemplo, exclusivamente internas ${ }^{35}$.

\section{c. Vigência e aplicação}

Dos três tipos de normas principais do Direito Europeu, o regulamento tem efeito mais facilmente inteligível e a vigência mais ampla: conforme o art. 189 II do Tratado CE o regulamento tem vigência geral, obriga com todas as suas partes e vigora imediatamente em todos os Estados-membros.

O direito primário, isto é, os tratados, seus protocolos e os princípios jurídicos comuns, sem dúvida, tem vigência imediata em todos os Estadosmembros, porém a sua aplicabilidade no caso concreto depende de que uma norma do direito primário seja suficiente mente clara, completa, incondicional, estabeleça um dever de fazer ou não fazer de uma pessoa ou de um Estado. membro e seja capaz de ser aplicada pelos órgãos e tribunais nacionais sem demais medidas estaduais ${ }^{36}$
A diretiva, como é dirigida só aos Estados-membros, vigora prioritariamente para eles, mas também para os orgãos estaduais e não tem efeito direto entre pessoas físicas ou pessoas jurídicas de direito privado; nesse sentido, não vigora no próprio território estadual de uma maneira geral e, por isso, tem vigência limitada ${ }^{37}$. Mas, como ver-seá, existem casos em que, mesmo se não for transformada pela ordem jurídica interna a diretiva deve ser aplicada pelos tribunais e demais órgãos estaduais.

\section{A diretiva como instrumento especial da integração jurídica}

\section{Nota Preliminar}

Através do instrumento da diretiva o Tribunal CE seguiu três caminhos para influenciar ordenamentos jurídicos nacionais em favor de uma harmonização deste sob a sombra do sistema europeu: a) a aplicação imediata (ou efeito direto) das diretivas não-transformadas, no âmbito das relações entre indivíduo e Estado; b) a indenização para indivíduos prejudicados por causa da não-transformação de diretiva e c) a exigência da interpretação do direito nacional de acordo com as diretivas.

\section{Aplicação da diretiva não- transformada como sanção}

\section{a. Necessidade de uma sanção}

As diretivas costumam estabelecer um prazo dentro do qual devem ser transformadas para o ordenamento jurídico interno. O Estado-membro que não transforma uma diretiva durante o prazo ofende o dever imposto pelo art. 189 III do Tratado CE.

A sanção, conforme o Tratado, art. 169, é o processo de quebra do Tratado. Trancorrido algum tempo, este processo provou ser uma sanção insuficiente ${ }^{38}$. Começando pelo próprio art. $189 \mathrm{III}$, o Tribunal CE desenvolveu outras sanções para a não-transformação de diretivas. $O$ ponto de partida para este desenvolvimento foi impedir o Estado-membro de usar o seu próprio comportamento indevido como argumento contra um cidadão prejudicado pela não-transformação. Seria abuso de direito por parte do Estado aproveitar-se da sua própria ofensa ao Tratado ${ }^{39}$.

\section{b. Sanção do efeito direto}

A sanção do efeito direto só surge em certos casos: primeiro, a diretiva deve ainda não ter sido transformada ou ter sido mal

31. Ainda não há jurisprudência suficiente sobre o princípio da subsidiaridade; comparar especialmente: Stephen Weatherrill Pau Beaumont, EC-Law, (2⿺ ed., Penguin Books, London 1995) pp. 15, 143, 247s; mais positivo: Beutler/Bieber/Pipkorn/Streil, (nota 1), p. 85

32. Emmert, (nota 15), p. 177; um bom exemplo que mostra como o Tribunal CE amplia a sua esfera de influência é o acórdăo TCE: 17/07/1997 Rs. C-28/95 (Leur-Bloem), Slg. 1997 I, 4161 (4199 ss.) onde acolhe um caso doméstico sob a sua competência.

33. Beutler/Bieber/Pipkorn/Streil, (nota 1), pp.96s.

34. Para o entendimento "europeu" ver Beutler/Bieber/Pipkorn/Streil, (nota 1), pp.96 s.; para o "diálogo" entre o Tribunal CE e os Tribunais nacionais, especialmente o Tribunal Constitucional da Alemanha (a jurisprudência de "Enquanto" - "Solange") ver Emmert, (nota 15), pp. 144 ss.

35. Emmert, (nota 15) p. 153

36. Emmert, (nota 15), p. 153

37. Comparar o entendimento mais amplo de Bach, (nota 23), pp. 1110 s., 1116.

38. Hans D. Jarass, Grundfragen der innerstaatlichen Bedeutung des EG-Rechts (Carl Heymanns Verlag, Köln et. al., 1994), p. 71; Stadie, (nota 7), p. 439.

39. TCE: 19/01/1992, Rs. 8/81, (Becker..Finanzamt Münster-Innenstadt) Slg. 1982, 53 (77, cifra 50). 
transformada, com prazo para transformação já expirado. Segundo, somente as normas suficientemente claras e incondicionais podem ter efeito direto. Terceiro (até há pouco tempo), a norma invocada tinha que favorecer o indivíduo numa relação entre indivíduo e Estado ${ }^{40}$ (hoje a sanção de efeito direto aplica-se em todas as relações entre indivíduo e Estado) ${ }^{41}$.

O Tribunal CE supera o sentido literal da norma do art. 189 III do Tratado CE, que não admite o efeito direto, aplicando o argumento do effet util do direito comunitário ${ }^{42}$ e acrescentando que a diretiva é norma obrigatória, como é o regulamento, o que justifica que a diretiva tenha um efeito parecido com a vigência ampla e imediata que o art. 189 II do Tratado CE estabelece para o regulamento ${ }^{43}$. Trata-se de uma aplicação ampla do método teleológico.

A sanção do efeito direto tem (ou tinha, pois, como se verá logo a seguir, alterou-se a jurisprudência do Tribunal $C E^{44}$ ) o vício da casualidade ${ }^{45}$ : depende do fato, de uma norma de uma diretiva não-transformada ter ou não caráter favorável para um indivíduo perante o Estado.
Além disso, há um outro problema, já mencionado acima ${ }^{46}$, quando se tratou do caráter específico da diretiva como norma jurídica com o fim_obrigatório: o efeito direto só surge caso a diretiva seja não-transformada, não-transformada completamente ou mal transformada. Quem decide sobre a qualidade da transformação e, assim, sobre a questão, principalmente, se o fim foi alcançado, é o Tribunal CE que, quando determina este fato (da qualidade da transformação), entra, profundamente, no regime jurídico nacional e tem a possibilidade de decidir, repetidas vezes, se o fim da diretiva ainda não se alcançou ${ }^{47}$.

\section{c. Quebra da idéia da sanção -}

\section{Art. 5 Tratado CE}

Mesmo depois de ter desenvolvido a aplicação imediata como sanção o Tribunal $\mathrm{CE}$, todavia, não parou. Ele afastou-se do argumento segundo o qual em que o indivíduo deve (e pode) invocar a norma da diretiva para seu proveito e estabeleceu que todos os órgãos estaduais devem aplicar a norma favorável em favor do indivíduo de ofício, mesmo que a norma não seja invocada ${ }^{48}$. Este novo argumento baseouse no art. 5 do Tratado CE, o qual, de uma

40. TCE: Rs. $8 / 81$ (nota 39), Jarass, (nota 38), 71, pp. 74 ss., tratando do problema de diretivas favorável a umas e desfavorável a outras pessoas nos pp. $83 \mathrm{ss}$.

41. Ver logo a seguir.

42. Ver acima II 1. c.

43. Antiga jurisprudência, ver TCE: 05/04/1979, Rs. $148 / 78$ (Ratth), Slg. 1979,1629 (1641s.).

44. Ver a seguir $\mathrm{c}$.

45. Um vício espalhado no Direito Europeu por ser por grande parte de origem judicial, Pagenkopf, (nota 7), p. 224

46. II 2. c.

47. Ver o exemplo na nota 26 para área do direito trabalhista e a decisăo TCE: 10/04/1984, Rs. 14/83, (v. Colson u. Kamann .l. Land Nordrhein-Westfalen), Slg. 1984, 1891

48. TCE: 22/06/1989, Rs. 103/88 (Fratelli Constanzo./. Stadt Mailand) Slg. 1989, 1839; reforçado pelo TCE: 14/12/1995, Rs. C-312/ 93 (Peterbroeck), Slg. 1995 I, 4599, que veta expressamente uma norma nacional de processo que proibe a consideração de certas questōes de Direito Europeu se nenhuma das partes as invoca dentro de um certo prazo.

Revista da Faculdade de Direito da UFRGS, v. 16, 1999 maneira genérica, determina o dever de todos os órgãos dos Estados-membros de tomar medidas para serem cumpridas às obrigações impostas pelo Tratado.

Num outro passo, o Tribunal estabe leceu que bastaria um dever claro dos órgãos dos Estados-membros de agir, determinado pela diretiva ${ }^{49}$. Deste modo, não é mais ne cessário um proveito para um indivíduo e também, admissível um prejuízo conseqüen te para um outro indivíduo ${ }^{50}$, ou até somen te um prejuízo para um indivíduo ${ }^{51}$.

Mesmo que este novo desenvolvimento recente tenha a vantagem de acabar com o vício da casualidade na aplicação do efeito direto por causa da dependência do proveito para um indivíduo ${ }^{52}$ ficam, ain$\mathrm{da}$, mais dois problemas.

Primeiro, - dado o caso - os órgãos estaduais, quer dizer, os seus próprios funcionários - teoricamente-, devem determinar sobre a qualidade $\mathrm{da}$ transformação, uma decisão complexa e difícil que exige demais ${ }^{53}$ deles. Contu- do, é uma decisão inevitável, pois só no caso da transformação insuficiente surge o efeito direto. Segundo, isso se confronta com a idéia da sanção, base originária de toda esta linha de argumentação, e daí o Tribunal CE tira a justificação principal para desconsiderar o sentido literal do art. 189 III do Tratado $\mathrm{CE}^{54}$ (a não ser que se presuma que o próprio estado sancione a ele mesmo).

\section{Indenização por falta de transformação}

Como as diretivas não vigoram diretamente no território nacional, mas só obrigam os órgãos estaduais a aplicá-las nas relações entre Estado e indivíduo, o efeito direto não adianta no caso das diretivas que harmonizam o direito privado ${ }^{55}$.

Apesar de tentativas de persuasão $0^{56}$, o Tribunal CE nunca aceitou ou concedeu o efeito direto entre pessoas físicas ou pessoas jurídicas de direito privado diretamente (efeito direto horizontal) ${ }^{57}$.

\section{TCE: 11/08/1995, Rs. C-431/92 (GroBkrotzenburg) Slg. 1996 I, 2189 (2224, cifra 40).}

50. Astrid Epiney, Unmittelbare Anwendbarkeit und objektive Wirkung von Richtlinien, DVBI. 1996, pp. 409-414, p. 413.

51. Wilfred Erbguth/ Frank Stollmann, Die Bindung der Verwaltung an die FFH-Richtlinie, DVBI. 1997, pp.453-458, p. 455

52. Ver acima $b$.

53. É interessante notar que o próprio Tribunal CE impôs o dever de transformação através da aplicação do efeito direto a todos os órgãos dos estados membros, mas não aceita a aplicação direta das diretivas pelos órgãos estaduais como medida certa da transformaçăo - talvez também por causa destas dificuldades-, TCE: 13/03/1997 (nota 22); comparar também Meinrad Dreher, Richtlinienumsetzung durch Executive und Judicative?, EuZW 17 (1997), pp. 522-525, p. 524.; neste sentido, também ver Monika Böhm, Voraussetzungen einer Staatshaftung bei Verstößen gegen primäres Gemeinschaftsrecht, JZ 1997, pp. 53-60, p. 56.

54. Assim também Hans-Jürgen Papier, Direkte Wirkung von Richtlinien der EG im Umwelt- und Technikrecht, DVBI. 1993, pp. 809. 814, p. 813.

55. M. Schmidt, (nota 2), p. 570

56. Ver por todos as propostas finais do Procurador-Geral Lenz no caso TCE: 14/07/1994, Rs. C-91/92 (Faccini Dorn), Slg. 1994 I, 3325 (3328 ss).

57. No caso citado na nota anterior pp. 3347 ss., o Tribunal recusa expressamente esta possibilidade, esta jurisprudência é continuada pelo acórdão TCE: 07/03/1996, Rs. C-192/94 (El Corte Inglés SA./. Cristina Blásquez Rivero), Slg. 1996 I, 1281 (1296 s.). 
Nesses casos, o Tribunal estabeleceu outro instrumento. Concede um direito de indenização caso um cidadão comunitário - de qualquer país da CE - tenha um prejuízo por causa de uma diretiva não ou mal transformada ${ }^{58}$. O Tribunal baseia esse direito à indenização no art. 189 II, em conjunto com o art. 5 Tratado CE, e exige que os tribunais nos Estados-membros assegurem este direito no quadro do direito da responsabilidade extracontratual nacional ${ }^{59}$.

Logo após a criação do direito à indenização, no caso de uma diretiva para harmonizar o direito civil, o Tribunal CE estendeu este direito a todos os casos em que um Estado-membro viola uma norma do direito comunitário ${ }^{60}$.

Como pré-requisitos da indenização, o Tribunal primeiro estabelece, que a norma violada deve ter o fim de conferir direitos subjetivos; segundo, a violação da norma pelo Estado-membro deve ser suficientemente qualificada; terceiro, que haja causalidade imediata entre a violação da norma comunitária e o dano das pessoas prejudicadas $^{61}$.

O pré-requisito da violação suficientemente qualificada sustitui o pré-requisito da culpa do funcionário nos casos de responsabilidade extracontratual do estado em alguns ordenamentos nacionais ${ }^{62}$. No âmbito da transformação de diretivas, este prérequisito de violação suficientemente qualificada considera-se preenchido quando, dentro do prazo, não houve nenhuma transformação ${ }^{63}$.

Deve-se, também, presumir que está preenchido este pré-requisito, se o Tribunal CE já anteriormente decidiu que a transformação é insuficiente ou mal feita ${ }^{64}$. Mais problemático é a presunção do preenchimento do pré-requisito no caso em que haja jurisprudência consolidada para assuntos semelhantes ${ }^{65}$.

Como esta argumentação não encontra base alguma, na letra da lei, isto é,nos artigos invocados, é um caso de desenvolvimento de direito praeter ou até contra legem. Além disso, causa problemas nas demais ordens jurídicas européias que não conheciam (pois agora, com esta jurisprudência nova, passam a conhecer) um direito de indenização do indivíduo contra o estado por falha legislatória ${ }^{66}$. Além disso, parece audaz estabelecer uma responsabilidade quase

58. TCE: 19/11/1991, Rs. C-6/90 u. C.9/90 (Francovich u. a.) Slg. 1991 I, 5357, continuado e desenvolvido por TCE: 05/03/1996, Rs. C-46/93 u C-48/93 (Brasserie du pêcheur u. Factortame III), Slg. 1996 I, 1029.

59. TCE, Rs. C- $6 / 90$ u. C-9/90 - nota anterior -. 5412, cifra 42 .

60. TCE: Rs. C-46/93 u C-48/93 (nota 58);ver o acordăo nacional conseqüente do BGH: 24/10/1997, NJW 1997, pp. 123-126.

61. TCE: Rs. C-46/93 u. C-48/93 (nota 58 ), 1149, cifra 51.

62. Jarass, (nota 38), pp. $117 \mathrm{~s}$.

63. TCE: 08/10/1996, Rs. C-178, 179, 188, 189, 190/94, (Dillenkofer u.a.) Slg. 1996 I, 4845 com demais referências à jurisprudência do Tribunal CE; Jarass, (nota 35), p. 118

64. Comparar Jarass, (nota 38), p. 117.

65. Como aconteceu no acórdão TCE: 05/03/1996 (nota 58), cifra 57; para uma discussão do caso ver Böhm, (nota 53).

66. Jarass, (nota 38), p.71; Böhm, (nota 53), p. 57 .

objetiva sem equilibrá-la através de um limite ${ }^{67}$.

Mesmo assim, é um instrumento cada vez mais consolidado que pode proteger de uma maneira eficaz os direitos dos turo do Direito Europeu ${ }^{68}$

\section{Diretiva e interpretação}

\section{a. Nota preliminar}

A diretiva como sanção $0^{69}$ originouse da relação entre o cidadão europeu e o Estado-membro, mesmo que se tenha afastado desta base. Os parágrafos seguintes serão dedicados ao efeito uniforme das diretivas em todas as relações jurídicas num Estado-membro, e, por conseguinte, no sistema jurídico nacional como um todo.

Este efeito se produz através da interpretação do direito nacional no sentido da diretiva, em consideração ao seu fim, independentemente do fato de se a diretiva foi transformada pelo ordenamento interno ou não ${ }^{70}$.

\section{b. Interpretação e aplicação}

De acordo com o art. 177 do Tratado CE, o Tribunal CE decide no processo indivíduos e, talvez, indique o caminho fu-

prejudicial sobre a interpretação do Tratado. Com isso, a própria aplicação da norma assim interpretada continua a caber ao tribunal nacional, como decidiu há décadas o próprio Tribunal $\mathrm{CE}^{71}$. Parece que hoje o Tribunal, tacitamente, ultrapassou a demarcação entre interpretação e aplicação do Tratado.

Como a maioria das ordens jurídicas européias não conhece a distinção entre interpretação e aplicação de direito ${ }^{72}$, esta distinção não produz demarcação, mas uma transição gradual: o jurista perante um conjunto de fatos e uma norma para aplicar a estes, não deixa os fatos sairem do seu campo visual quando tenta indagar o que quer dizer a norma ${ }^{73}$.

Em qualquer caso, o Tribunal CE não pode interpretar as normas do Direito Europeu sem referir-se às normas do direito nacional, cuja aplicabilidade interesse ao processo. Dessa maneira, no fundo, o Tribunal CE não só interpreta o Direito Europeu, mas também, ao indagar o direito nacional, interpreta este ${ }^{74}$.

Ao dar a entender ao tribunal nacional como deve interpretar o seu próprio direito nacional, o que é o resultado certo do procedimento da interpretação, o Tribunal

67. Como, por exemplo, conhece o direito alemão em todas as leis novas que estabelecem responsabilidade objetiva; diz-se, porem que o pressuposto da violação qualificada tem efeito tão limitante que torna improvável ser preenchido em muitos casos no futuro, Böhm, (nota 53), p.60.

68. Ver neste sentido M. Schmidt (nota 3).

69. Ver acima II 2. a. - c.

70. Ver Bach, (nota 23), p. 1116 que chama este efeito objetivo em contraste com o efeito subjetivo que vem da sanção.

71. TCE v. 27/03/1963 Rs. 28-30/62 (Da Costa \& Schaake. .I. Niederländische Finanzverwaltung) Slg. 1963, 63.

72. M. Schmidt, (nota 2), p. 593.

73. Ver Reinhold Zippelius, Einführung in die juristische Methodenlehre (3ª. ed., C. H. Beck, München, 1980), pp. 115ss.; Josef Esser Vorverständnis und Methodenwahl in der Rechtsfindung (Athenäum Verlag, Frankfurt am Main, 1970), pp. 40ss..

74. Jarass, (nota 38), pp. 89 ss. assume, no meu entender, errôneamente, que somente o tribunal nacional interpreta o direito nacional. 
CE, propriamente, aplica o Tratado CE ao direito nacional, interpretando-o conforme as diretivas européias e utilizando, necessariamente, os seus métodos interpretativos (e não os métodos interpretativos nacionais) ${ }^{75}$.

\section{c. Interpretação e solução de conflito de normas}

Esta jurisprudência dá lugar à per gunta, se o Tribunal, ao orientar os tribunais nacionais na interpretação do seu direito nacional, simplesmente resolve o conflito entre as normas européias e nacionais em favor da primazia da norma euro péia $^{76}$, como acontece, de maneira direta no caso das diretivas no âmbito das rela ções entre indivíduo e Estado ${ }^{77}$. Em outras palavras: depois de ter decorrido o prazo para a transformação, uma diretiva suficientemente clara aplica-se - de fato - ime diatamente em todos os Estados-membros e a todas as relações jurídicas, dado o caso, não só em favor, mas também em detrimento do cidadão comunitário ${ }^{78}$. No caso da diretiva, que afeta as relações entre o indi víduo e o Estado, este procedimento chama-se aplicação imediata ou efeito direto.
Quando se trata de uma relação entre pessoas privadas o fenômeno é designado "in terpretação". O fim - como o resultado - é o mesmo em ambas as hipóteses ${ }^{79}$.

Porém, mais recentemente, o Tribunal CE modificou suá posição na hipótese da interpretação de normas aplicáveis nas relações entre pessoas físicas ou pessoas jurídicas de direito privado.

Como desenvolveu e reforçou a sanção da indenização ${ }^{80}$ por dano sofrido pelo cidadão comunitário por causa da transformação mal feita de uma diretiva, o Tribunal prefere hoje este caminho à interpretação contra legem ${ }^{81}$ do direito nacional $^{82}$. A nova posição do Tribunal pode descrever-se da seguinte maneira:

No caso da diretiva, que regula relações entre indivíduo e Estado, todos os ser viços públicos dos Estados-membros têm que aplicar as normas da diretiva que são incondicionais e suficientemente claras a partir do momento em que houver decorrido o prazo para a transformação, independentemente de uma vantagem ou desvantagem para as pessoas afetadas pela diretiva.

75. Um exemplo bem claro é o caso TCE: 14/04/1994, Rs. C-392/92 (Christel Schmidt), Slg. 1994 I, 1311; para uma crítica ver M. Schmidt (nota 2), p. 596 com demais indicaçōes para a discussão do caso; semelhante o caso TCE: 13/11/1990, Rs. C-106/89 (Marleasing), Slg. 1990 I, 4135

76. Assim M. Schmidt, (nota 2), p. 584

77. Ver acima II 3. B. e c. juntamente com III 2. b. e c.

78. Ver acima III 2. b. ec.

79. Comparar, também, Epiney, (nota 50), p. 410; quanto a uma aproximação de conceitos do efeito direto (também chamado subjetivo, que vem da sanção) e do efeito objetivo que pode resultar neste tipo de interpretação, no âmbito de direito público. 80. Ver acima jurisprudência citada na nota 58.

81. Como de fato aconteceu nos casos TCE: 10/04/1984 (nota 47) e de 14/04/1994 (nota 75) e especialmente, de 13/11/1990 (nota 75); comparar Bach, (nota 23), p. 1116 para uma posição semelhante.

82. Assim, mas com um entendimento mais favorável do acórdão (Marleasing), (nota 75): Christian Baldus/ Rainer Becker, Haustürgeschätte und richtlinienkonforme Auslegung, ZEuP 1997, pp. 874-889, pp. 883 ss.
- No caso da diretiva no âmbito do direito privado, os tribunais dos Estadosmembros face a uma relação entre pessoas físicas ou pessoas jurídicas de direito privado, a qual deve ser aplicada uma diretiva européia, devem esforçar-se na interpretação do direito nacional para alcançar um resultado de acordo com a diretiva não ou mal transformada. Se os tribunais nacionais não conseguirem um resultado deste tipo, cabe à parte prejudicada entrar em juízo para conseguir uma indenização. ${ }^{83}$

\section{d. Abalo de direito interno}

Como a integração na Comunidade Européia pelo Tribunal CE somente pode acontecer de caso a caso, é dificultada a formação de um sistema próprio. Além disso, o caminho escolhido pelo Tribunal tem o efeito de abalar os sistemas internos dos Estados-membros de uma maneira imediata, mesmo que seja só em determinados pontos.

Como exposto acima ${ }^{84}$, a interpretação das diretivas pelo Tribunal CE, necessariamente, leva consigo a interpretação do direito nacional no âmbito das diretivas pelф mesmo Tribunal. Este fato em si já mostra efeito interessante para o sistema nacional. Entretanto, há outro efeito mais interessante e importante. Por causa da estrutura do funcionamento especial da primazia do $\mathrm{Di}$ reito Europeu ${ }^{85}$, as normas e os institutos jurídicos nacionais só se tornam inaplicáveis na zona de vigência da diretiva; porém, vigoraram e são aplicadas fora dessa zona ${ }^{86}$.

Um exemplo para este efeito é o caso Marleasing ${ }^{87}$, em que se tornou inaplicável, parcialmente, a norma sobre as causas de nulidade de contratos. Tratava-se de uma norma de direito civil que, segundo a sistemática do direito espanhol, era aplicada antigamente no âmbito de direito societário e foi pelo Tribunal CE, afastado deste âmbito de aplicação.

Outro exemplo comparável é o caso v. Colson und Kamann ${ }^{88}$. Tratou-se do $\$ 611$ a BGB ( Código Civil Alemão), versão antiga, que tinha entrado na lei para transformar a diretiva 76/207/CEE ${ }^{89}$ sendo, pois, um caso de uma diretiva mal transformada, e não de uma diretiva não-transformada ${ }^{90}$. $\mathrm{O}$ $\S 611$ a BGB, versão antiga, prescrevia uma indenização do interesse negativo, no caso de uma empresa recusar-se a contratar uma pessoa por causa de discriminação sexual ${ }^{19}$.
83. Comparar TCE: 14/07/1994 (nota 56) e comentário de Rolf Herber, ZEuP 1996, pp. 121-125, pp. $123 \mathrm{s.}$

84. III 2. b. e 4. b.

85. III 3. b.

86. Parece que o Tribunal $C E$ já se deu conta deste problema e sugere como solução a ampliação dos seus poderes de interpretação e de avaliação de direito nacional fora do alcance do Direito Europeu, ver o acórdão Leur-Bloem, (nota 32).

87. Nota 75.

88. Nota 47 .

89. Nota 26 .

90. Ver Birk, (nota 26), pp. $388 \mathrm{ss.}$

91. A mais recente versão desta norma - depois do acordão do Tribunai CE - estabelece uma quantia fixa de indenização. 
A regra do $\$ 611$ a BGB estava baseada no princípio da culpa in contrahendo, que estabelece uma indenização do interesse negativo ao contratante prejudicado pela falta da formação ou nulidade posterior do vín culo contratual $^{92}$.

O Tribunal CE decidiu que o inte resse negativo não era uma indenização suficiente, por ser um quantia pequena ${ }^{93}$ que não iria desanimar a empresa disposta a violar o princípio de não-discriminação. Por isso, a lei implementada para transfor mar a diretiva mencionada pela ordem jurídica nacional era mal feita, não podia alcançar e realizar o fim da diretiva. Assim o Tribunal CE mudou a aplicabilidade de princípio da culpa in contrahendo no siste ma alemão.

Os casos de abalo de direito interno não se limitam ao âmbito do direito priva do: o direito alemão possui uma norma $\$ 48$ VwVfG (lei sobre processos na administração pública) que protege o cidadão na se guinte situação: ele recebe subvenções de boa-fé, emprega o dinheiro para finalidade prevista e depois essas subvenções comprovam-se como injustificadas. Há uma linha de jurisprudência do Tribunal CE que man da inaplicável esta norma do $\$ 48 \mathrm{VwVfG}$ no caso das subvenções (subvenções do próprio Estado-membro, não da $\mathrm{CE}$ )

abrangidas pelos artigos 92 a 94 Tratado $\mathrm{CE}^{94}$.

Ainda que nestes casos de intervenção do Tribunal CE nos ordenamentos jurídicos internos dos Estado-membros, mais exatamente nos institutos jurídicos nacionais, estes institutos e estruturas não deixem de existir, eles mudam de caráter por serem complementados ou cortados de uma maneira contra-sistemática. Seria necessário redimensioná-los, o que não acontece. Todos os casos, os precedentes, que anteriormente estavam agregados à norma ou ao instituto jurídico nacional dando a ela ou a ele o sentido, o entendimento, específico ${ }^{95}$ têm que ser reexaminados antes de ser novamente aplicados no procedimento da interpretação da norma para o entendimento de instituto jurídico nacional.

\section{e. O problema dos métodos}

Embora sejam semelhantes, os métodos interpretativos de cada sistema jurídico diferem entre si. Por isso, o Tribunal $\mathrm{CE}$ na interpretação do Tratado $\mathrm{CE}$ não pode recorrer a um método único preexistente. Ele deve desenvolver os seus próprio métodos. Neste procedimento, ele recorre com freqüência aos conceitos preexistentes nos sistemas nacionais. Assim, o Tribunal CE, na tarefa de preencher estes Beck, München 1996) $\$ 249$ cifra 17.

93. O que não é necessariamente assim: dependendo do caso concreto o interesse negativo é capaz de ser maior do que o interesse

94. Ver Pagenkopt, pp. 219 ss., com indicação da jurisprudência do TCE; para uma exposiçăo mais abrangente, comparar Stadie, (nota 7), especialmente pp. $439 \mathrm{~s}$

95. Theodor Geiger, Vorstudien zu einer Soziologie des Rechts ( $2^{\mathrm{a}}$ ed. pelo Paul Trappe, Luchterhand, Neuwied am Rhein 1964) pp. 249 ss., p. 251, para a ação recíproca entre norma e prededentes.

Revista da Faculdade de Direito da UFRGS, v. 16, 1999
92. Como também estabelecem os $\$ \$ 122$ e $307 \mathrm{BGB}$, ver Otto Palandt Helmut Heinrichs, Bürgerliches Gesetzbuch, (55a ed., C. H. positivo, Palandt Heinrichs, (nota 92), \$249 cifra 17. conceitos com conteúdo distinto daquele que os mesmos têm nos sistemas nacionais, causa, em primeiro lugar, uma confusão de conceitos.

Em segundo lugar, a diferença no significado do conceito que surge, volta a ter efeito no ordenamento a que pertencia e lá abala o sistema dos conceitos e dos métodos $^{96}$. Outro abalo de métodos surge - como já foi exposto 97 - no caso em que o Tribunal CE estabelece o sentido da norma nacional aplicando seus próprios métodos sem ocupar-se com os métodos nacionais ${ }^{98}$.

Nos casos em que o Tribunal CE já aplicação do direito nacional interpretado conforme as diretivas contrárias ao resultado alcançado e alcançável pelos métodos nacionais ${ }^{99} \mathrm{O}$ Tribunal, de fato, destrói os métodos específicos de aplicação de direito que formam a base de cada ordenamento jurídico de um Estado.

\section{Conclusões e uma sugestão}

Demonstrou-se a força e a contribuição eminente do Tribunal CE na integração jurídica na Europa. Apresentou-se, também, a idoneidade impressionante da estabalece o resultado do procedimento de diretiva como instrumento dessa integração.

Contudo, além disso, pode-se ver como o processo encaminhado pelo Tribunal, utilizando as diretivas, tem o efeito de abalar os sistemas jurídicos dos Estados-membros de uma maneira difusa e imprevisível. Este fenômeno: primeiro, é crítico e perigoso do ponto de vista do Essenvolvimento realizado, por um tribunal que desconhece as regras de auto-limitação inerentes ao sistema common law, transforma-o em um órgão altamente político, papel que não cabe à Justiça; terceiro, deixa perguntar se este caminho está de acordo com as constituições e com as leis de adesão à Comunidade Européia dos Estados-membros ${ }^{100}$. Finalmente, tem que se examinar, também, se o desenvolvimento concorda com o princípio de subsidiaridade estabelecido no art. $3 \mathrm{~b}$ Tratado $\mathrm{CE}^{101}$.

Estas averiguações agravam-se pela falta de transparência e de discussão pública dos efeitos expostos. Este conjunto de fatos, a longo prazo, põe em perigo a continuação bem-sucedida do processo de tado de Direito; segundo, prova que o de-

96. Ver, por exemplo, Pagenkopf, (nota 7), p. 220, trabalhando os conceitos "Ermessen" e "Beurteilungsspielraum", quer dizer, "discrição" $e$ "margem de juízo" no direito administrativo alemão.

97. Ver acima, III 4. c.

98. Para uma justificação desta atitude frente aos métodos nacionais no interesse da integração européia, ver Grundmann, (nota 20), p. 282.

99. Ver os acórdãos do Tribunal CE Christel Schmidt e Marleasing (nota 75).

100. Stadie, (nota 7), p. 440; Pieper, (nota 7), pp. 935 ss, com indicaçăo de demais fontes sobre a discussão.

101. Além de conter o princípio de subsidiariedade, este artigo, na sua parte $I$, assenta os limites da atividade da Comunidade pelo àmbito do Tratado e, na sua parte Ill, estabelece o princípio da proporcionalidade para as medidas da CE; para a incompatibilida. de de diretivas muito detalhadas com o princípio de subsidiariedade ver a observaçăo interessante de Christian Armbrüster, Ein de de diretivas muito detalhadas com o princípio de subsidiariedade vera
Schuldvertragsrecht für Europa?, RabelsZ 60 (1996), pp. 72-90, p.84.

Revista da Faculdade de Direito da UFRGS, v. 16, 1999 
integração européia. Nota-se já, especialmente, que os tribunais nacionais negam apoio à nova ordem jurídica européia ${ }^{102}$.

Existem várias soluções possíveis para este sério problema, umas no pata mar político, outras no patamar jurídico. Deixando de lado o patamar político, que aqui não se enquadra, segue uma suges tão:

Primeiro: fixar em cada diretiva nova a parte imediatamente aplicável no momento em que houver decorrido o prazo para a transformação, independentemente do tipo da diretiva, regulando-se o direito público ou o direito privado. Este novo procedimento deve basear-se numa nova versão do art 189 III do Tratado CE a fim de autorizá-lo. Conjuntamente, deveria ser melhorada a publicação das diretivas, pelo menos nas partes marcadas, para a aplicação imediata.

Segundo: facilitar, simplificar e acelerar o processo de quebra do Tratado do art. 169 Tratado CE (para os casos de não- transformação das partes não automaticamente aplicáveis das diretivas).

Terceiro: estabelecer, expressamente no Tratado CE, a responsabilidade extracontratual dos Estados-membros e ao mesmo tempo limitá-la aos casos concretos e exatamente definidos como de quebra do dever da transformação.

E, por último, vetar para o futuro, expressamente, outras possibilidades de aplicação imediata no âmbito do art. 189 Tratado CE ou de responsabilização fora do âmbito do art. 169 Tratado CE.

Pois, quanto mais a Comunidade Européia se aproxima da configuração de um Estado federal, em vez de uma comunidade de estados, tanto mais tem que adaptar medidas e estruturas que cabem a um Estado de Direito.

Espera-se que os países, que, no momento, moldam e formam o Mercosul tenham condições de evitar os desvios do desenvolvimento europeu e iniciem logo em um caminho certo.

\title{
O Ministério Público como Fiscal da Lei no Processo Civil
}

\author{
Fosé e Maxia Oesheinex
}

(Livre-Docente pela Faculdade de Direito da UFRGS, Desembargador aposentado, Professor Orientador do Curso de Mestrado da PUC-RS).

O Ministerio Público pode atuar, no processo civil, como autor; raramente como réu (refere-se, usualmente, a hipótese de rescisoria de sentença proferida em ação de nulidade de casamento por ele proposta).

Pode atuar como curador especial de incapaz, de réu preso ou de revel fictamente citado (CPC, art. $\left.9^{\circ}\right)$.

Nossa atenção volta-se especialmente para outra forma de sua atuação em processo civil, ou seja, como fiscal da lei (custos legis) conforme previsäo do artigo 82 do CPC

Qual a natureza dessa espécie de atuação? Qual o regime da nulidade decorrente da falta de sua intervenção? Eis ai o objeto do presente estudo

\section{Generalidades sobre o Ministério Público}

iz a Constituição que o Ministério Público é instituição permanente, essencial à função jurisdicional do Estado, incumbindo-lhe a defesa da ordem jurídica, do regime democrático e dos interesses sociais e individuais indisponíveis (art. 127).

Todavia, soa falsa a nota de essencialidade à função jurisdicional do Estado. Fosse verdadeira, não poderia haver processo sem intervenção do Ministério Público. Mas esta somente é exigida em casos determinados. Tal como a lei ordinária, também a Constituição diz, às vezes, mais do que pretendia - magis dixit quam voluit (disse mais do que queria).

São funções institucionais do Ministério Público, conforme dispõe o artigo 129 da Constituição:

"I - promover, privativamente, a ação penal pública, na forma da lei;

II - zelar pelo efetivo respeito dos Poderes Públicos e dos serviços 